\title{
A MULTI-AGENT DECISION SUPPORT METHOD FOR SELECTING WAY TO DISPOSE KITCHEN GARBAGE IN CONDOMINIUM
}

\author{
Shinichi Fujita* and Hiroyuki Tamura** \\ *Environmental Pollution Control Center of Osaka Prefectural Government \\ 1-3-62 Nakamichi, Higashinari-Ku, Osaka 537-0025, Japan \\ FujitaS@mbox.pref.osaka.jp \\ **Faculty of Engineering, Kansai University \\ 3-3-35 Yamate-cho, Suita, Osaka 564-8680, Japan \\ H.Tamura@kansai-u.ac.jp
}

Keywords: Life Cycle Assessment (LCA), Disposer, Waste Treatment, GHGs, Descriptive AHP

Summary: In this paper, a Life Cycle Management (LCM) for the residents for selecting the way of disposing domestic kitchen garbage is proposed. The alternative ways to dispose the kitchen garbage are evaluated based on the items related to the global environmental problems, comfort of the life and cost. The model of descriptive extension of Analytic Hierarchy Process is used for the multi-agent decision making process in the case of reconstruction of a condominium. In this paper, in order to adjust the preferences of multi-agent, a method based on the Delphi questionnaire is applied.

\section{Introduction}

It is important to live a life which considered preservation of the environment. Total amount of municipal waste that generally consists of the domestic waste, the paper and kitchen garbage from office, was about 50 million-tons/year in 2002 in Japan. The kitchen garbage held about a quarter of the total municipal waste, and the most of kitchen garbage is incinerated at the refuse incineration plant of each municipal in Japan. Therefore, to reduce the wastes is important from the viewpoints of effective use of limited resources and preservation of the environment.

On the other hand, to live the hygienic and convenient life is the important factor for the resident. The use of a disposer in a house had been restrained in Japan for controlling the load on the public sewerage, but the regulation was relaxed in 2000 , and the use of disposer with satisfied wastewater standard has been spreading. Then, we develop the method to support decision making to select the way to dispose kitchen garbage. To evaluate the preference of the resident for selecting the way to dispose the kitchen garbage, alternative methods are settled. The amounts of emissions of GHGs for each alternative are estimated using Life Cycle Assessment (LCA) analysis.

The system to evaluate the preference of resident in selecting the way of disposing domestic kitchen garbage is a large scale system that includes many items and their relations are complicated. Then, Analytic Hierarchy Process (AHP) is used. AHP is a convenient method to analyze the system that includes many items and their relations are complicated (Saaty, 1980). Though, it is known that AHP has a shortcoming to come across irrational rank reversal phenomena. When a new copy alternative is added to an existing set of alternatives or when an alternative is removed from the existing set of alternatives, the rank of the remaining alternatives may change (Belton and Gear, 1983).

Then, the model of descriptive extension of Analytic Hierarchy Process is used in this paper. In this model, the rank reversal phenomena are legitimately observed and explanatory, and the model is called Descriptive Analytical Hierarchy Process (D-AHP) (Tamura, et al, 2000). 
The model using D-AHP was applied to support decision making to select the way to dispose kitchen garbage for the single house (Fujita and Tamura, 2004). In this paper, we develop the method to support decision making to select the way to dispose kitchen garbage in the case of reconstructing the condominium. In order to adjust the preferences of multiple residents in the condominium, a method based on the Delphi questionnaire is applied.

\section{The Outline of the Study}

\subsection{The Concept of the LCM}

The basic concept of the study is shown in Figure 1. In this paper, the residents who live in the Condominium are selected as the object to the study.

At the first step, the amounts of emissions of GHGs for each alternative are estimated. In this estimation, the GHGs emissions at the stage to supply the raw materials, to produce or to transport the facility, to use or to operate the facility, and to dispose the wasted facility are estimated (LCA).

At the second step, the preferences of resident for each alternative are evaluated, where the items for LCM evaluation are related to the emissions of GHGs, cost, and comfort of the life. Further, the adjustment of multiple decision makers is performed.

We call life cycle management (LCM) for this analysis, and including LCA and LCM, we call LCM in wide sense.

\subsection{Alternative methods to dispose the kitchen garbage}

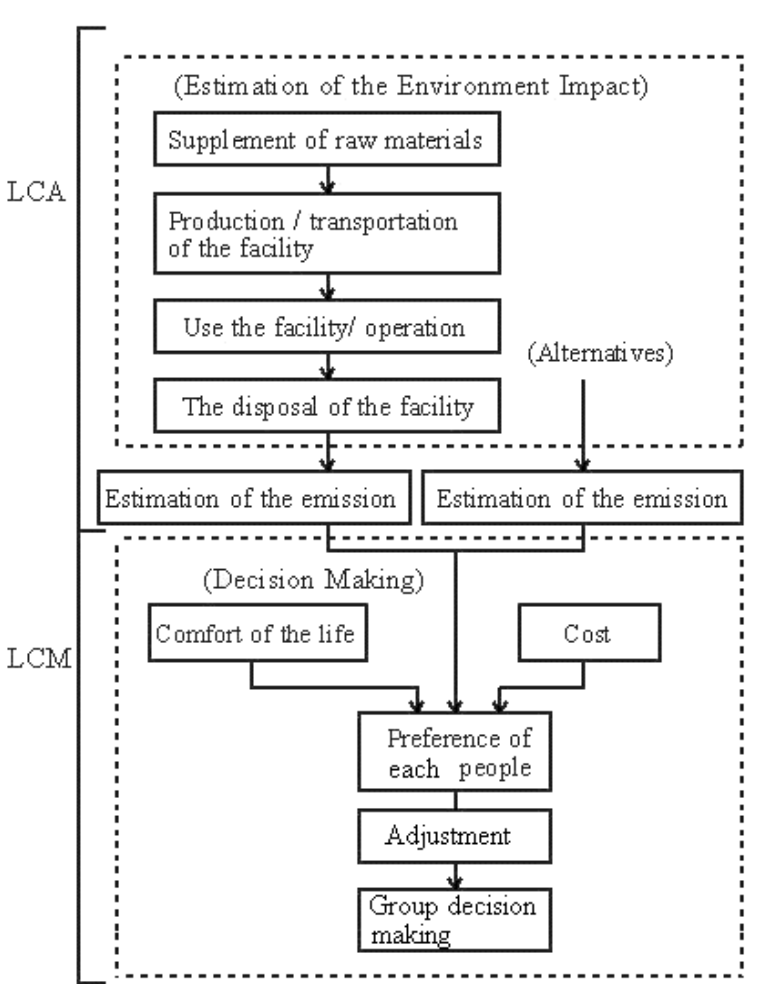

Fig. 1 The concept of the LCM

The alternative scenarios to dispose the kitchen garbage are the following three methods.

Scenario 1: The kitchen garbage is discharged as the municipal waste, and the waste is carried to the municipal refuse incineration plant periodically, and incinerated, which is the current method.

Scenario 2: The kitchen garbage is crushed with disposer and it is discharged into public sewerage after sewage treatment.

Scenario 3: The half of kitchen garbage is put into compost with the large scale composting facility, and the compost is used for the plants in condominium's garden. The remainder of kitchen garbage is discharged as the municipal waste, and the waste is carried to the municipal refuse incineration plant periodically, and incinerated, which is the current method.

\section{LCA Analysis for the Emission of GHGs for Each Scenario}


Though $\mathrm{CO}_{2}$ emission due to the kitchen garbage is not included in the national GHGs emission according to the IPCC guideline (IPCC, 1995), we also estimate the GHGs including CO2 emission due to the kitchen garbage. In this paper, the objective condominium in which 80 households live, and the average household consists of 3.0 persons. The GHGs estimations from the construction of the plant or facilities are not considered.

\subsection{The Emission of GHGs of Scenario 1}

The annual GHGs estimations due to the transportation of kitchen garbage per a family are calculated from the unit GHGs emission rate due to diesel track (Ministry of the Environment, Japan, 2003). In this case, it is assumed that combustible waste including kitchen garbage is collected twice per week by the diesel track loading capacity being 2 ton.

The annual $\mathrm{CH}_{4}$ and $\mathrm{N}_{2} \mathrm{O}$ emissions due to the incineration of kitchen garbage per a family are calculated from the kitchen garbage yielded per a family and the coefficient of GHGs emission due to the incineration of combustible wastes (Ministry of the Environment, Japan, 2003b; Land, Infrastructure and Transport Government, Japan, 2002).

The annual $\mathrm{CO}_{2}$ emission due to the incineration of the kitchen garbage is calculated from the rate of carbon composition in the kitchen garbage (Hirai, et al, 2001) and the kitchen garbage yielded per a family per a year.

The annual GHGs emissions due to the transportation of the incineration ashes of the objective kitchen garbage are also calculated although they were as small as they could be disregarded. In this study, the GHGs estimations due to the landfill of the ashes are not calculated.

\subsection{The Emission of GHGs of Scenario 2}

The GHGs emissions due to transportation of the facility and setting the facility are calculated from the unit GHGs emission rate due to diesel track, and they are divided by the durable years.

The GHGs emissions due to the operation of the disposer facility are estimated from the annual electric and water works consumption due to the facility (Land, Infrastructure and Transport Government, Japan 2002) and the unit GHGs emission rate of the electric and water works consumptions (Ministry of the Environment, Japan, 2003; Land, Infrastructure and Transport Government, Japan, 2002).

The GHGs emissions due to the domestic sewage treatment are estimated from the unit GHGs emission rate for sewerage treatment tank (Ministry of the Environment, Japan, 2003; Land, Infrastructure and Transport Government, Japan 2002). Then the GHGs emissions due to the public sewage treatment are estimated from the unit GHGs emission rate for public sewage ((Ministry of the Environment, Japan, 2003; Land, Infrastructure and Transport Government, Japan, 2002). The GHGs emissions to dispose the sludge are also calculated.

\subsection{The Emission of GHGs of Scenario 3}

The emission of GHGs due to dispose the half of the kitchen garbage is estimated as the same procedure as scenario 1 , because the half of garbage is incinerated the municipal refuse incineration plant.

The remainder of the garbage is put into compost with the large scale composting facility, and the compost is used to the plants in condominium's garden. The GHGs emissions due to transportation of the composting facility and setting the facility are calculated from the unit GHGs emission rate due to diesel track, and they are divided by the durable years.

The GHGs emissions due to the operation of facility are calculated from the annual electric and water works consumption due to the facility. The GHGs emissions due to the fermentation of the garbage are 
estimated from the amount of carbon in the garbage. In this study, the GHGs from garden due to the fertilizing are not included.

\subsection{The Emission of GHGs of Each Scenario}

The emissions of GHGs calculated for each alternative are shown in Table 1. The fifth column in Table 1 indicates the total values of GHGs, which show the $\mathrm{CO} 2$ equivalents based on GWP100 (IPCC, 1995). The numbers in the parenthesis mean the case where the $\mathrm{CO} 2$ emission due to the incineration of the kitchen garbage is included.
Table 1 The emissions of GHGs from each scenario

\begin{tabular}{|l|c|c|c|c|}
\hline & $\begin{array}{c}\mathrm{CO} 2 \\
\mathrm{~kg} / \mathrm{year}\end{array}$ & $\begin{array}{c}\mathrm{CH} 4 \\
\mathrm{~kg} / \text { year }\end{array}$ & $\begin{array}{c}\mathrm{N} 2 \mathrm{O} \\
\mathrm{kg} / \text { year }\end{array}$ & $\begin{array}{c}\text { Total } \\
\mathrm{kgCO} / \\
\text { year }\end{array}$ \\
\hline Scenario 1 & $\begin{array}{c}7.078 \\
(119.750)\end{array}$ & 0.000 & 0.004 & $\begin{array}{c}8.266 \\
(118.678)\end{array}$ \\
\hline Scenario 2 & $\begin{array}{c}5.390 \\
(73.713)\end{array}$ & 0.265 & 0.000 & $\begin{array}{c}10.957 \\
(79.281)\end{array}$ \\
\hline Scenario 3 & $\begin{array}{c}22.571 \\
(94.339)\end{array}$ & 0.000 & 0.002 & $\begin{array}{c}23.166 \\
(94.934)\end{array}$ \\
\hline
\end{tabular}

\section{The Evaluation of the Preferences of the Residents}

\subsection{The algorithm of D-AHP}

The algorithm of D-AHP is as follows (Tamura, et al, 2000):

Step 1. Multiple criteria and multiple alternatives are arranged in a hierarchical structure.

Step 2. Compare the criterion pairwise which is arranged in the one level higher level of alternatives. Eigenvector corresponding to the maximum eigenvalue of the pairwise comparison matrix is normalized to sum to 1 . The priority obtained is set to be preference characteristics represent basic priority.

Step 3. For each criterion, aspiration level is asked to DM. A hypothetical alternative that gives aspiration level for all the criteria is added to a set of alternatives. Including this hypothetical alternative, pairwise comparison matrix for each criterion is evaluated. Eigenvector corresponding to the maximum eigenvalue is normalized so that the entry for this hypothetical alternative is equal to 1 .

Step 4. If consistency index $C . I=0$ for each comparison matrix, preference characteristics, that is, basic priority is used as the weighting coefficient for each criterion. If $C . I . \neq 0$ for some criteria the priority for these criteria is revised by using following equation.

$$
\begin{aligned}
& w_{i}=w_{i}^{B} \times C^{f(C . I .)} \\
& 0 \leqq C \leqq 1 \\
& 0 \leqq f(C . I .) \leqq 1
\end{aligned}
$$

where, $w_{i}^{B}$ is basic weight for element $i$ obtained from preference characteristics, and $C$ is the status characteristics which denotes the average importance of alternatives calculated by following equation.

$$
C=\left|\log _{\rho}\left(\prod_{i=1}^{n} w_{i}\right)^{1 / n}\right|
$$

Step 5. If some priorities are revised taking into account the status characteristics, the priority for each criterion is normalized to sum to 1 . 
Step 6. Overall weight is evaluated.

Step 7. Evaluate pairwise comparison matrix of criteria with respect to each criterion in the higher level. If some pairwise comparison matrices are not consistent, evaluate status characteristics and revise the priority.

\subsection{The Evaluation Using D-AHP}

In order to investigate the validity of the model, we ask five housewives who live in the condominium. Hierarchical structure to evaluate the preference of a housewife to select the method to dispose the kitchen garbage is shown in Figure 2.

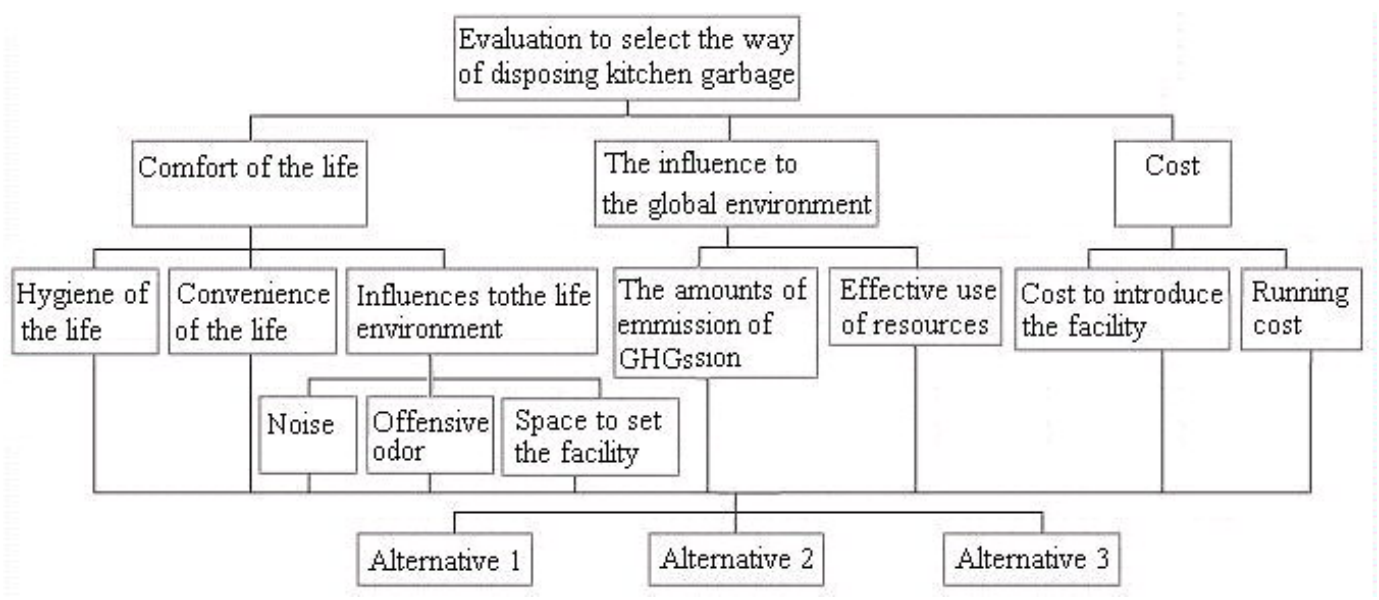

Fig.2 The hierarchical structure to evaluate the preferences of housewives who live in condominium

\subsection{The Result of the Evaluation due to the first questionnaires}

Based on the hierarchical structure shown in Fig. 2 , we performed pairwise comparison using the algorithm explained in section 4.1.

In Table 2, we show the result of the evaluation for the group preference of the alternative scenarios using by D-AHP. In this table, the weight of the group, consisted from housewives who live in condominium, is calculated from the arithmetic average of each housewife's weight for alternative level.
Table 2 The result of evaluation due to the first questionnaires

\begin{tabular}{|l|cc|}
\hline & Weight & Rank \\
\hline Scenario 1 & 3.153 & 1 \\
\hline Scenario 2 & 2.513 & 2 \\
\hline Scenario 3 & 2.419 & 3 \\
\hline Aspiration level & 1.000 & - \\
\hline
\end{tabular}

\subsection{The Result of the Evaluation due to the Second questionnaires}

In Table 2, the result is derived from merely the arithmetic average of each housewife's weight, and it is hardly to say the adjustment of the members of the group. To adjust the preferences of the members of the group who live in condominium, a repetition questionnaire method based on the Delphi questionnaire is applied.

Show the distribution of the alternatives' weights under the criterion which is the one level higher level of alternatives, the second questionnaires are performed. 
In Table 3, we show the result of the evaluation based on the second questionnaires for the group preference. In this table, the weight of the group, consisted from housewives who live in condominium, is calculated from the arithmetic average of each housewife's weight as the same as the first questionnaires.

The distributions of weights under the criterion which is the one level higher level of alternatives level, become narrower in the case of the second questionnaires. And it means that the adjustment between members proceeded.
Table 3 The result of evaluation due to the second questionnaires

\begin{tabular}{|l|cc|}
\hline & Weight & Rank \\
\hline Scenario 1 & 3.080 & 1 \\
\hline Scenario 2 & 2.493 & 3 \\
\hline Scenario 3 & 2.520 & 2 \\
\hline Aspiration level & 1.000 & - \\
\hline
\end{tabular}

\section{Conclusion}

The AHP is considered useful of the decision support for the selection of the way of disposing the kitchen garbage in the case of reconstruction of a condominium. The methods to dispose the kitchen garbage are generally changeable, so using D-AHP is useful in this case.

In this paper, it is shown that the method based on the Delphi questionnaire is valid to the adjustment between members, however the evaluations are based on only five samples.

We would perform the evaluation based on more samples, hereafter.

\section{References}

Belton, V. and T. Gear (1983). On a shortcoming of Saaty's method of analytic hierarchies, OMEGA The International Journal of Management Sciences, Vol. 11, No. 3, pp. 228-230.

Fujita, S. and H. Tamura (2004). Life Cycle Management for Selecting the Way of Disposing Domestic Kitchen Garbage, Preprints of the 10th IFAC/IFORS/IMACS/ IFIP Symposium on Large Scale Systems, Osaka, Japan, pp.124-129, 2004 .

Hirai, H, M. Murata, S. Sakai and H. Takatsuki (2001). Life Cycle Assessment on Food Waste Management and Recycling, Journal of the Japan Society of Waste Management Experts, Vol.12, No. 5, pp. 229-234. (in Japanese)

IPCC (1995). Climate Change.

Land, Infrastructure and Transport Government, Japan (2002). A draft report of the method to consider the judgment of the influence if the use of disposer is spreaded, Sewerage Department, City and Regional Development Bureau of Ministry of Land, Infrastructure and Transport Government. (in Japanese)

Ministry of the Environment, Japan (2003). http://www.env.go.jp/earth/ondanka/santeiho/kento/h1408/ index.html. (in Japanese)

Saaty, T. L. (1980). The Analytic Hierarchy Process, McGraw-Hill, New York

Tamura, H., S. Takahashi, I. Hatono and M. Umano (2000). On a behavioral model of analytic hierarchy process for modeling the legitimacy of rank reversal, In Y.Y. Haimes and R. E. Steuer, eds. Research and Practice in Multiple Decision Making, Lecture Notes in Economics and Mathematical Systems 487. Springer-Verlag, Berlin, pp. 173-184. 